\title{
Cidadania e trabalho na sociedade da informação: uma abordagem baseada na competência informacional
}

Elisangela Marina dos Santos

\section{Bibliotecária}

Elizabeth Andrade Duarte

Bibliotecária. Mestre em Ciência daInformação pelo Programa de PósGraduação em Ciência da Informação da Escola de Ciência da Informação da UFMG. Especialista (Pós-Graduação Lato Sensu) em Didática do Ensino Superior pela Faculdade Pitágoras.

Nilson Vidal Prata

Bibliotecário da Assembléia Legislativa do Estado de Minas Gerais. Mestre em Ciência da Informação pelo Programa de Pós-Graduação em Ciência da Informação da Escola de Ciência da Informação da UFMG.

Apresenta uma reflexão a respeito dos temas cidadania e trabalho, relacionando-os à necessidade de desenvolvimento da competência informacional como elemento de transformação do indivíduo, sob a ótica da Economia Política da Informação. Define competência informacional e menciona quais são seus benefícios e desafios. Aborda sua importância como elemento capaz de proporcionar a inserção do indivíduo na Sociedade da Informação, não apenas como um consumidor passivo de informações, mas principalmente como agente ativo e provocador de mudanças.

Palavras-chave: Competência informacional; Economia Política da Informação; Cidadania; Trabalho; Sociedade da Informação 


\section{Citizenship and work in the information society: an approach based on the Information Literacy}

The present article aims at promoting a reflection about the subjects Citizenship and Work. The themes are related to the need of developing information literacy as an element of transformation of the individual from the Political Economy of Information perspective. Information literacy is defined; its benefits, challenges are mentioned as well as its importance as an element capable of providing the individual insertion in Information Society not only as a passive information consumer, but also as an active agent of changes.

Keyworks: Information Literacy; Economy Politics of the Information; Citizenship; Work; Information Society.

Recebido em 06.12.2007 Aceito em 13.10.2008

\section{Introdução}

Este artigo objetiva desenvolver uma reflexão sobre as questões ligadas à cidadania e ao trabalho na Sociedade da Informação, numa abordagem baseada na competência informacional - Information Literacy - e sob a ótica da Economia Política da Informação.

De acordo com Mosco (1998), a Economia Política da Informação pode ser compreendida como 0 estudo das relações sociais, particularmente as relações de poder, que mutuamente constituem a produção, a distribuição e o consumo de recursos, incluindo os recursos informacionais. Numa visão mais genérica, é o estudo do controle entendido como a organização interna da sociedade e os progressos de adaptação às mudanças - e da sobrevivência social - modo como os indivíduos produzem aquilo que é necessário para a reprodução e continuidade sociais. Nesse aspecto, Aun e Câmara (2005) enfatizam que diferentes autores definem a economia da informação como uma economia que tem a informação como principal insumo e produto, sendo dependente das novas tecnologias de informação e caracterizada pelo aprendizado contínuo. Sua emergência é global, facilitada pelo desenvolvimento dessas tecnologias e da criação de redes informacionais, podendo trazer muitos benefícios por sua versatilidade, capacidade de armazenamento e de deslocamento em tempo real.

No bojo das transformações econômicas proporcionadas pelo franco desenvolvimento das tecnologias de informação e comunicação (TIC), 
surge a necessidade do desenvolvimento de novas competências que tornem as pessoas capazes de lidar com o construto informação. Tais competências se tornaram elementos essenciais para a inclusão dos indivíduos nesta sociedade em mutação, denominada Sociedade da Informação ou do Conhecimento. A evolução das TIC nos últimos anos, além de contribuir para o aumento exponencial da quantidade de informações disponíveis, teve considerável impacto nas formas de sua disponibilização e disseminação. A era da informação e do conhecimento se caracteriza pela superação das barreiras temporais e territoriais através da globalização. Os indivíduos têm seus relacionamentos reconfigurados por uma rede de proporções mundiais. A sobrevivência nesse cenário requer aptidão e o desenvolvimento de habilidades para que o indivíduo seja capaz de acessar, compreender e fazer melhor uso das informações disponíveis.

Diversas iniciativas vêm sendo empreendidas para que o acesso à informação deixe, cada vez mais, de se constituir em obstáculo ao desenvolvimento de pessoas e países. Ao mesmo tempo, novas ponderações surgem: quantos indivíduos realmente se encontram qualificados para recuperar e selecionar, dentre a enorme quantidade de informações disponíveis, aquelas que são realmente relevantes? Como essa competência - ou a ausência dela - influi no exercício do nosso papel de cidadãos conscientes de nossos direitos e obrigações? Como pode nos tornar aptos a participar competitivamente do mercado de trabalho, utilizando as novas ferramentas e metodologias trazidas pela modernidade? São essas questões que este artigo pretende abordar, sem, contudo, a pretensão de oferecer respostas prontas ou corretas, mas sim a de promover um convite à reflexão sobre o desenvolvimento individual e coletivo nessa nova sociedade e os problemas que nela se apresentam.

\section{Sociedade da informação: uma compreensão}

A denominada Sociedade da Informação introduziu mudanças sem precedentes na economia mundial: a explosão informacional, as inovações tecnológicas e a velocidade dessas mudanças influenciaram profundamente a cadeia produtiva, requerendo assim mais "mentes brilhantes" e menos "músculos" para a acumulação de capital. A velocidade da ampliação do uso da informação como recurso econômico teve impacto direto na geração de empregos e nos investimentos em produção. Nesse âmbito, ressalta-se que o conceito de Sociedade da Informação tornou-se popular a partir da década de 1990, em razão do

esforço dos governos de se preservar uma sustentabilidade econômico-social, pois ela [a Sociedade da Informação] surge com o vislumbrar de novas oportunidades de emprego, de educação à distância e aprendizagem ao longo da vida, suporte ao desenvolvimento de bons serviços públicos de informação, acesso e concessão de recursos para todos e de 
coesão social para as diferentes regiões do mundo (AUN, 2001, p. 51).

Sob esse olhar, identifica-se tal sociedade como aquela na qual empresas/organizações recorrem cada vez mais à informação para aumentar sua eficácia, sua competitividade, estimulando a inovação, obtendo melhores resultados e também aprimorando a qualidade dos bens e serviços que produz. Percebe-se aqui o desenvolvimento de atividades cada vez mais voltadas para a informação, aumentando a escala do seu valor agregado e beneficiando a economia do país. Tais argumentos se relacionam diretamente com a compreensão de Moore (1999), que caracteriza a Sociedade da Informação pelo desenvolvimento de informação na economia, tendo como função a satisfação da demanda geral por produtos e serviços de informação. Uma parte desse setor refere-se à infra-estrutura tecnológica, ou seja, às redes de telecomunicações e computadores. O conhecimento emerge como elemento central do processo gerador de desenvolvimento econômico e social.

Assim, a Sociedade da Informação conferiu à informação e ao conhecimento uma importância nunca antes observada, pois passaram, na maioria dos casos, a ser tratados como mercadoria, e, conseqüentemente, como portadores de valor monetário. Essa mudança de status foi e é sustentada, sobretudo, pelo desenvolvimento das novas tecnologias de informação e comunicação (TIC) que, se por um lado propiciaram as condições materiais que facilitaram a produção e a divulgação de informações e conhecimentos, por outro trouxeram em seu bojo o problema da explosão informacional, caracterizada por Saracevic (1996) como incoercível crescimento da informação e de seus registros, inicialmente nas áreas ligadas à ciência e à tecnologia e atualmente em todos os campos da atividade humana. Nesse contexto é que surge o conceito de competência informacional, abordado a seguir.

\section{Competência informacional: evolução do conceito}

A competência informacional (Information Literacy) consiste em um conjunto de habilidades necessárias para interagir com a informação, seja ela no espaço acadêmico, no trabalho, nas questões particulares, constituindo-se em capacidade chave dentro do processo de aprendizagem. Em outras palavras, representa a habilidade de reconhecer quando existe uma necessidade de informação; a capacidade de identificar, recuperar, avaliar e usar eficazmente essas informações no âmbito da tomada de decisão.

De acordo com Dudziak e Ferreira (2001), a expressão Information Literacy foi cunhada pela primeira vez na literatura de Ciência da Informação há cerca de 30 anos, mais especificamente no ano de 1974, em um relatório intitulado "The information service environment relationships and prioritie", de autoria do bibliotecário americano Paul Zurkowski. Como presidente da Information Industry Association (IIA), 
Zurkowski integrava a equipe da National Commission on Libraries and Information Science, a qual tinha como propósito estabelecer as diretrizes para um programa nacional de acesso universal à Information Literacy, a ser concluído até 1984, face ao cenário de transformações. A tese defendida por ele consistia em que pessoas treinadas na aplicação dos recursos de informação em seu trabalho podem ser chamadas de competentes ('literates') em informação. Isso porque elas aprenderam técnicas e habilidades para utilização de um grande número de ferramentas de informação assim como as fontes primárias, de modo a criar as soluções para seus problemas. O desenvolvimento da concepção de Information Literacy ocorreu no início dos anos 80, associado às práticas dos postos de trabalho e às noções e regras da qualificação para o emprego. A primeira parte dos anos 90 foi um período de institucionalização e de racionalização do conceito, quando as modificações no mundo do trabalho proporcionaram o equilíbrio entre a gestão das qualificações e o reconhecimento das competências, iniciandose a procura de métodos e a realização das primeiras pesquisas. Já no final dos anos 90, a competência toma lugar no contexto da gestão de recursos humanos e se informatiza, adquirindo também importância crescente dentro do debate social (MIRANDA, 2004).

No Brasil, a competência informacional desenvolveu-se em torno da preocupação, por parte de bibliotecários, com questões sócioeducacionais e ações culturais bibliotecárias. É importante ressaltar que, apesar dos conceitos de competência informacional e ação cultural bibliotecária serem comuns, não se trata de um mesmo conceito. A competência informacional está relacionada com a geração de determinadas habilidades em vários contextos. Já a ação cultural bibliotecária está ligada a iniciativas de inclusão, de resistência, de contrahegemonia, ou seja, exige, conforme aponta Cabral (1999), um profissional com um perfil diferenciado e um tipo de formação que seja complementada com disciplinas de outras áreas, além da biblioteconomia. Este tipo de ação pode ser considerado como campo profissional extremamente rico e transformador, em que os sujeitos passam da condição de meros consumidores de cultura para a de produtores de informação e conhecimentos. Como expoentes na área podem ser destacados: Cerdeira (década de 70); Breglia, Flusser, Macedo, Milanesi, Rabello, Targino (década de 80); Alves, Cysne, Faria, Fernandes, Litto, Martinez, Obatta, Perroti (década de 90) Neves (2000). Destacam-se ainda projetos como o Programa de Serviços de Informação em Educação (PROESI - ECA-USP), direcionado para bibliotecas interativas, e o Núcleo de Comunicação e Educação (NCE - ECA-USP), com foco nas interrelações entre Comunicação e Educação.

A Competência Informacional pode ser conceituada também como um conjunto de competências profissionais (habilidades, atitudes, comportamentos que permitem o desenvolvimento da organização no cumprimento de sua missão), competências organizacionais (técnicas, formas de trabalho, competências de serviços) e competências-chave (habilidades e tecnologias cuja marca de autenticidade é a integração), 
que possam estar ligadas ao perfil de um profissional da informação ou de uma atividade baseada intensivamente em informação (MIRANDA, 2004).

Segundo Aun e Câmara (2005), o indivíduo com competência informacional é aquele que reconhece a necessidade de, diante de uma questão, buscar informação; reconhece que a informação completa e precisa constitui a base para a tomada de decisões inteligentes; identifica fontes de informação potenciais e desenvolve estratégias para a pesquisa de informação com sucesso; acessa fontes, tanto as tradicionais como aquelas disponíveis a partir de outras tecnologias; avalia a qualidade da informação; organiza a informação para aplicação prática; integra informação nova em um corpo de conhecimentos previamente existente; utiliza a informação para o exercício do espírito crítico e para a resolução de problemas.

Campello e Abreu (2005) complementam ao argumentarem que para ser capaz de construir um novo paradigma e de contribuir para a educação de pessoas competentes em informação, o próprio bibliotecário deve ser competente em informação e dominar as habilidades necessárias para realizar o processo de pesquisa adequadamente. Nesse contexto, amplia-se o conceito de educação de usuários e o novo pensamento sobre o papel a ser exercido pelo profissional bibliotecário no processo de aprendizagem.

\section{Benefícios da competência Informacional}

Fazendo-se uma análise sob o ponto de vista dos benefícios que a Competência Informacional pode proporcionar aos indivíduos, pode-se ressaltar as "expertises", as habilidades e as capacidades. Correia (2002, p. 6) esquematiza com clareza tais benefícios:

- expertise para lidar com as tecnologias de informação em contextos informacionais - capacidade de identificar todas as etapas em um trabalho com informação;

- expertise para lidar com o ciclo informacional - o indivíduo é capaz de gerenciar a informação e sua interface com as tecnologias;

- habilidade para mapear competências informacionais capacidade de agregar valor ao negócio e contribuir para a criação de seu diferencial competitivo;

- capacidade para aperfeiçoar competências informacionais - o indivíduo é capaz de focar em competências genéricas, agrupar semelhanças, identificar necessidades futuras.

\section{Política nacional de informação}

Grande parte dos programas de inclusão digital no Brasil tem focado sua atuação no uso da tecnologia e no acesso à informação, sem a preocupação de capacitar os indivíduos para o desenvolvimento de Competência Informacional. Nesse sentido, Aun e Câmara (2005, p. 1) afirmam que: 
A Competência Informacional proporciona o aumento do uso de tecnologias da informação na transição para uma sociedade da informação [...] possibilitando a milhares de pessoas confrontar obstáculos, demandas e competências profissionais, requisitos fundamentais nesta sociedade de redes virtuais, ampliando a inserção social e global do cidadão.

Os autores salientam que a definição de uma política de inclusão digital deve contemplar quatro aspectos fundamentais:

- o entendimento das especificidades locais e regionais, bem como do conteúdo informacional que as caracterizam;

- a necessidade de estratégias distintas para as diferentes sociedades (é uma política voltada para a sobrevivência ou para a inovação?);

- a identificação, o estudo e o compartilhamento do conhecimento comum envolvido;

- a identidade e os valores sócio-culturais da sociedade como um todo.

Nesta proposta, os dois primeiros aspectos são fundamentais para o estabelecimento desses programas, e os dois últimos lidam com 0 compartilhamento e os valores sócio-culturais que pertencem a determinada comunidade. Somente o compartilhamento e os valores sócio-culturais são capazes de garantir a base necessária para o desenvolvimento estruturado de todos os membros da cadeia: indivíduos, empresas, comunidades e nação.

\section{Cidadania e Competência Informacional}

O conceito de cidadania deve ser compreendido dentro de uma perspectiva de construção histórica, ou seja, seu desenvolvimento ocorreu, e em certa medida ainda vem ocorrendo, através de um processo de lutas sociais intensas, muitas vezes marcadas pelo uso de diversas formas de violência. Trata-se de um conceito dinâmico, não estanque, construído paulatinamente e que assume diferentes significados para cada contexto em que é analisado. Em linhas gerais, pode-se considerar que é a participação na vida social e política que confere ao indivíduo o status de cidadão. Conforme enfatizado por Targino (1991, p. 152), "um homem só é realmente homem quando pode exercer sua faculdade de julgar para realizar escolhas éticas, tanto em relação a seus próprios atos, como em relação à comunidade em que vive". Percebe-se, pois, que o exercício da cidadania extrapola o momento do voto, ultrapassando também a noção pura e simples da submissão a deveres e da titularidade de direitos. Mamede (1997, p. 223), menciona que cidadão é o sujeito ativo na cena política, sujeito reivindicante e provocador da mutação do direito. Neste sentido, participação é uma palavra-chave para a promoção da cidadania. Para este autor, cidadania é uma relação, não é uma coisa que uma pessoa possa ter e outra não, pois requer compromisso com a 
comunidade e com o bem-estar do próximo. Assim, solidariedade é outra palavra-chave.

Depreende-se daí que a informação é um dos pressupostos básicos para o exercício da cidadania. É por meio do acesso a informações que o cidadão tem condições de conhecer e cumprir seus deveres, bem como de entender e reivindicar seus direitos. Somente através de informação os indivíduos podem contribuir, participar e ocupar seu espaço na sociedade, assim como acompanhar, avaliar e questionar as ações do Estado com o objetivo de promover 0 bem comum. Fala-se muito que vivemos na chamada "sociedade da informação", advento intimamente relacionado às discussões sobre cidadania nos dias atuais. Mas o que isso efetivamente significa para os cidadãos que fazem - ou deveriam fazer - parte dessa sociedade?

Significa conviver com um paradoxo caracterizado pela dificuldade de obtenção de informações em meio à abundância delas. Atualmente, é o excesso de informações, muito mais que a sua falta, que se constitui em problema e que ameaça o exercício da cidadania, pois o caos informacional cria obstáculos para o acesso a conteúdos relevantes para resposta a uma determinada questão, seja ela referente aos direitos, aos deveres ou às formas de participação do cidadão enquanto membro de uma comunidade. Esse contexto, além de tornar mais complexo o exercício da cidadania, ao mesmo tempo evidencia a importância do desenvolvimento de competências relacionadas ao acesso e ao uso de informações. Cidadãos que possuem Competência Informacional compreendem a necessidade de informações de qualidade para 0 tratamento de problemas e questões inerentes às suas próprias vidas, à comunidade e à sociedade. Além disso, estão mais preparados para fazer com que esta mesma sociedade perceba a importância da sua participação em todas as arenas onde se desenrola o jogo democrático, que, conforme já mencionado, não se esgota com o exercício do voto.

O desenvolvimento de competências informacionais deve priorizar a educação para a cidadania, em seus distintos componentes - formal, informal e permanente -, como aspecto fundamental para a construção das sociedades democráticas, criando uma cidadania culta e preparando os indivíduos para se envolverem de forma ativa e efetiva em tudo o que diga respeito à administração do seu país, não se limitando a aceitar passivamente o que é decidido pelos outros. A capacidade de acesso e de uso da informação vem se consolidando como principal elemento para o desenvolvimento econômico e social, além de requisito para o exercício da cidadania.

A educação para a cidadania deve ser promovida desde as escolas do ensino básico, associando o potencial da educação digital aos recursos e métodos educativos tradicionais. Ao mesmo tempo, torna-se imprescindível desenvolver políticas de promoção e incremento das competências em informática entre crianças e adultos vítimas de exclusão (social e digital), proporcionando espaços onde o acesso à Internet seja gratuito ou de custo reduzido. 
Somente cidadãos informados, que tenham acesso a ensino de qualidade, a diversos meios de informação e aos modernos recursos tecnológicos, podem desenvolver competências informacionais que Ihes propiciem uma participação plena nas sociedades do conhecimento, contribuindo com estas de forma eficaz a partir da integração entre o local, onde a participação é mais ágil, e os níveis nacional e global.

Finalizando essa análise, é importante fazer menção à proposição de Correa (2002) sobre a subdivisão da Competência Informacional relacionada à cidadania. Para esta autora, um cidadão pode envolver-se em grupos. Um deles é o que localiza e acessa a informação, e que compreende e usa a informação que obtém. É considerado como mais fácil de ser atingido e prima por reconhecer a necessidade de informação (ter consciência daquilo que se conhece, reconhecer o que não se sabe e identificar o fosso existente), por distinguir formas de solucionar 0 problema (saber que fontes de informação podem satisfazer a necessidade), por construir estratégias de localização (saber como desenvolver e refinar estratégias de pesquisas) e por localizar e acessar (conhecer formas de encontrar fontes de informação e instrumentos de pesquisa para acessar o conteúdo e absorvê-lo).

Outro grupo é o que se distingue por uma maior dificuldade de capacitação devido à necessidade de conhecimento especializado, pois a maioria dessas especializações carregam consigo linguagens ou jargões próprios de uma área: comparar e avaliar (saber como aferir a relevância e a qualidade da informação pesquisada); organizar, aplicar e comunicar (saber de que forma associar os conhecimentos novos a conhecimentos já retidos e resultantes de experiências anteriores, de modo a tomar decisões e ser capaz de transmitir aos outros conhecimento proveniente dessas ações e decisões, se necessário); sintetizar e criar (saber de que forma associar conhecimentos novos a conhecimentos adquiridos, de modo a fornecer novas perspectivas e criar novos conhecimentos).

Enfim, o desenvolvimento de competências para que as pessoas tenham capacidade de buscar, recuperar e filtrar as informações, promovendo sua apropriação crítica, é fator primordial para que possam utilizá-las como elemento de emancipação individual, essencial à formação de cidadãos atuantes. O desafio das sociedades atuais é o de admitir, na era do conhecimento, cada vez mais pessoas com capacidade cada vez maior de acesso à informação e também à especialização profissional. A cidadania, aliás, está intimamente relacionada à profissionalização, uma vez que sem trabalho uma pessoa não consegue ser integralmente cidadã. O mundo do trabalho, assim como o da cidadania, vem sofrendo significativas mudanças no bojo da sociedade da informação, exigindo das pessoas adaptação e desenvolvimento de novas competências informacionais para a constituição de uma força de trabalho capacitada.

\section{Trabalho e Competência Informacional}

O trabalho constitui-se um fator essencial na vida social, visto que as relações sociais giram em torno das questões laborais, sejam as que se 
referem aos aspectos culturais, técnicos, ou não. O mesmo define o tempo para as outras atividades, pois as trocas sociais são feitas em função do tempo de duração do trabalho. "O trabalho é, na verdade, a essência do homem. E a idéia de trabalho não se separa da idéia de sociedade, na medida em que é com os outros que o homem trabalha e cria a cultura" (RIOS, 2001, p. 33). Como atividade de transformação da natureza, ou seja, de produção de cultura, faz-se presente desde as sociedades mais remotas, dado seu caráter essencial para a sobrevivência da humanidade.

$\mathrm{Na}$ moderna concepção, o trabalho, principalmente com o advento do capitalismo, adquire o caráter de regulador das relações sociais. Com a revolução industrial, no século XIX, os indivíduos saem das corporações de oficio, nas quais detinham o conhecimento de todo o processo de produção, para as fábricas, onde têm que se adequar às questões de horário, produtividade, etc., produzindo para o capitalista, sem contudo ter a consciência da produção como um todo. Nesse sentido, o trabalhador, que dominava o processo do seu próprio trabalho, é transferido para a fábrica, onde trabalha para e com outros indivíduos, e não sabe como funciona todo o processo produtivo.

Já com o advento da chamada sociedade da informação ocorre uma transformação substancial na organização do trabalho. As novas tecnologias proporcionam maior controle, produtividade e, sobretudo, modificações no fazer do trabalhador, o qual tem que se adaptar a esse novo contexto. O trabalhador deixa de ser uma mera peça do processo produtivo para participar e agir na criação e modificação de práticas estabelecidas. Essa mudança traz em seu bojo novas exigências de qualificação do trabalhador para sua inserção no mercado laboral.

Segundo Tomasi (2002, p. 6), a competência é caracterizada pela mobilização de saberes, que se congregam em "saber", "saber - fazer" e "saber ser". O primeiro se refere aos conhecimentos das regras; o segundo à experiência da ação; e o terceiro ao comportamento e conduta do indivíduo. A noção de competência se aplica ao indivíduo isoladamente, dotado de especificidades que o distinguem dos demais, contrapondo-se à idéia de qualificação, que denota uma qualidade coletiva. Nesse sentido, a negociação empregador/empregado torna-se individual e não coletiva, diminuindo o poder de negociação da classe trabalhadora. Difunde-se a competição entre os trabalhadores e a idéia de incapacidade dos que não conseguem ingressar no mercado. Enfaticamente, a noção de competência exerce...

[...] função precisa de marcar a desigualdade numa esfera que não é mais aquela tradicional da ideologia burguesa (a desigualdade natural das capacidades e talentos), mas uma outra produzida pela sociedade planificada organizada; a desigualdade entre detentores do saber e os despossuídos (CHAUÍ, 2003, p.147). 
Dessa forma, é salutar discutir a Competência Informacional ligada ao mundo do trabalho, dado que ela está relacionada à mobilização das capacidades intelectuais dos sujeitos. No contexto do trabalho, a Competência Informacional é aquela que habilita os indivíduos para lidar com todas as fontes de informação, no sentido de organizar, filtrar e selecionar o que de fato é importante para a tomada de decisões no ambiente organizacional. Segundo Siqueira (2003), pode-se inferir a Competência Informacional em contexto no qual existe tendência a mudanças de tarefas de cunho manual e das consideradas como de execução, em feitos de informação e comunicação, exigindo do homem novo: maior capacidade cognitiva, manuseio de informações e ampliação das atividades com foco no conhecimento. Ainda nessa direção, Castells (2005) salienta que uma conjetura importante da teoria original do pósindustrialismo refere-se à ampliação das profissões ricas em informação, como os cargos de administradores, profissionais especializados e técnicos, representando o foco da nova estrutura ocupacional.

Sendo assim, com o uso intensivo da tecnologia e a valorização do trabalho imaterial, ou seja, aquele no qual o intelecto sobressai em detrimento da materialidade ou da força física empregada para a realização das tarefas, tem-se a Competência Informacional como fator chave nas relações de trabalho, dado que o trabalhador, nesse contexto, atua em rede. Mas, para isso, o trabalho informacional exige cooperação, atuação em equipe, autonomia e responsabilidade dos trabalhadores, 0 que não se consegue apenas com o uso das novas tecnologias (CASTELLS, 2005).

Considerando inegável a flexibilidade proporcionada pelas novas tecnologias, tanto para o capital quanto para uma parcela de trabalhadores do conhecimento, percebe-se que:

A implementação da 'produção sem gorduras de pessoal' não elimina o interesse das multinacionais por locais de produção de baixos salários, mas elas não precisam mais deslocar-se milhares de quilômetros para achar esses locais. O efeito combinado das novas tecnologias e das modificações impostas à classe operária, no tocante à intensidade do trabalho e a precariedade do emprego, foi proporcionar aos grupos americanos e europeus a possibilidade de constituir, com a ajuda de seus estados, zonas de baixos salários e de reduzida proteção social [...] (CHESNAIS, 1996, p. 35).

Esta proposta vai ao encontro dos interesses capitalistas de exploração do trabalho alheio, principalmente nos países pobres. 0 trabalhador que conta com certas garantias, sob a tutela da lei, perderia seus direitos em favor de uma autonomia de negociação, ou negociação pela competência. O trabalhador competente terá emprego, enquanto aquele que não tem competência, "por sua culpa", fica à margem do mercado de trabalho. Esse discurso atende às necessidades de sustentação do capital, principalmente das multinacionais, que necessitam de mão de obra barata para manter sua competitividade. O maior 
prejudicado neste processo é o trabalhador, que conta apenas com sua competência para garantir seu posto de trabalho, em vista do sucateamento dos sindicatos enquanto instituições coletivas de defesa dos interesses da classe trabalhadora.

Nessa perspectiva, se percebe que este mercado, em constante mudança, tem exigido cada vez mais comprometimento por parte dos trabalhadores, principalmente na aquisição de novas competências, dentre elas a Competência Informacional, numa via de mão dupla que, se em uma direção vai de encontro aos interesses capitalistas, em outra constitui elemento essencial para a manutenção da empregabilidade do trabalhador, uma vez que é muito difícil - senão impossível - sobreviver fora desse sistema.

\section{Considerações finais}

Atualmente, para alavancar o desenvolvimento, os governos devem ater-se às novas necessidades impostas pela Sociedade da Informação. Um enfoque especial, conforme vimos neste estudo, deve ser dado ao aspecto educacional. Torna-se necessário que haja um planejamento de longo prazo, envolvendo a elaboração de uma política pública de informação, sólida e abrangente, com ampla participação da sociedade e que considere a formação educacional dos indivíduos. Esse processo deve ser implementado tanto no nível da educação formal, quanto informal, incluindo ações de aprendizado ao longo da vida, uma vez que, em razão da velocidade com que as mudanças ocorrem hoje, torna-se necessário que o aprendizado seja constante, em prol da própria sobrevivência do indivíduo.

Uma política de desenvolvimento de competências informacionais, então, constitui-se como um projeto de longo prazo. É preciso trabalhar na formação de uma nova cultura, onde os indivíduos tenham, de fato, um bom nível de Competência Informacional, obtendo melhores condições de enfrentar os desafios que a sociedade da informação vem colocando e, assim, de representar melhor seu papel enquanto cidadãos e membros de um mercado de trabalho altamente competitivo.

O conceito de sociedade da informação - ou qualquer outro nome que receba - não é um consenso, estando longe disso mesmo em relação às terminologias utilizadas para designá-la. Para além da questão terminológica, que não é a mais importante, há uma série de visões conflitantes acerca desse fenômeno moderno, consubstanciadas nas opiniões de autores otimistas, pessimistas e daqueles que adotam uma postura de neutralidade em relação ao tema, na tentativa de não pender para qualquer dos lados, se é que isso é possível.

Pelo que foi exposto neste artigo, pode-se inferir que, principalmente nos países periféricos, ainda há muito a avançar no sentido de se construírem "sociedades competentes em informação" - e não apenas de aderir a uma sociedade da informação que busca homogeneizar as culturas em benefício dos países globalizadores e em detrimento dos "globalizados". As questões capazes de afetar, tanto o mundo do trabalho 
quanto o exercício da cidadania, vêm sofrendo significativas mudanças no bojo dessa sociedade, exigindo das pessoas adaptação e desenvolvimento de novas competências, principalmente as informacionais. Possuir Competência Informacional não é um requisito que se restringe aos profissionais que lidam especificamente com a informação, mas que se aplica a todos. O que fica evidente é que o cidadão e o trabalhador da sociedade da informação precisam estar cientes das questões ora apresentadas e que lhes exigem a adoção de novas posturas, na tentativa de selecionar, dentre o caos informacional, as informações que contribuam para o processo de seu crescimento pessoal e profissional.

Shera (1977), ao discorrer sobre sua proposta de uma epistemologia social, já alertava que, assim como a necessidade de informação orienta o indivíduo, também orienta sociedades. Atingindo a emancipação pessoal, seja pelo exercício efetivo da cidadania ou pela inserção plena no mercado de trabalho - aspectos que não se excluem, antes se complementam -, espera-se que o indivíduo esteja apto a participar da construção de sociedades de informação, em que os recursos do conhecimento, informação e comunicação, sejam reconhecidos e protegidos como legado e patrimônio comuns de toda a humanidade, e devem, portanto, estar acessíveis a todos sob condições justas. Sociedades que incentivem o compartilhamento do conhecimento, em vez de sua privatização e exploração comercial.

Ao finalizar, fazemos coro às palavras de Lévy (1999, p. 45), que afirma que:

Longe de se uniformizar, a Internet [símbolo e principal instrumento da sociedade globalizada] abriga a cada ano mais línguas, culturas e variedade. Cabe apenas a nós continuar a alimentar essa diversidade e exercer nossa curiosidade para não deixar dormir, enterradas no fundo do oceano informacional, as pérolas de saber e de prazer - diferentes para cada um de nós - que esse oceano contém.

Por último, gostaríamos de enfatizar que, através da conjunção desses esforços individuais, poderemos vislumbrar sociedades em que as informações, os conhecimentos, a cooperação e a solidariedade humanas sejam considerados elementos essenciais, onde se promovam não só a criatividade individual mas também a inovação e a inteligência coletivas. Sociedades que garantam e promovam a diversidade cultural e lingüística e o diálogo intercultural em ambientes livres de discriminação, exploração, violência e ódio.

\section{Referências}

AUN, M.; CÂMARA, M. A. From lacking until sustainability: informatics inclusion as an option for freedom. mar. 2005. 10p. Disponível em: $<$ www.globaledevelopment.org/papers/FromLackingUntilSustainability.pdf $>$. Acesso em: 18 maio 2005. 
AUN, M. Antigas nações, novas redes: as transformações do processo de construção de políticas de informação. 2001. 208f. Tese (Doutorado em Ciência da Informação) - Escola de Comunicação, Universidade Federal do Rio de Janeiro, Rio de Janeiro, 2001.

CABRAL, A. M. R. Ação cultural possibilidades de atuação do bibliotecário. In: VIANNA, M. M.; CAMPELLO, B.; MOURA, V. H. V. Biblioteca escolar: espaço de ação pedagógica. Belo Horizonte: EB/UFMG, 1999. p. 39-45.

CAMPELLO, B.; ABREU, V. L. F. G. Competência informacional e o papel do bibliotecário na mediação da informação: uma perspectiva teórica. Perspectivas em Ciência da Informação, Belo Horizonte, v.10 n.2, p. 178193,jul./dez. 2005. <http://64.233.169.104/search?q=cache:TV1BJ4N1vc]:www.eci.ufmg.br/ pcionline/index.php/pci/article/view/2/150+competencia+informacional+b ernadete+campello\&hl=pt-BR\&ct $=c \mid n k \& c d=1 \& \mathrm{gl}=\mathrm{br}>$. Acesso em: $21 \mathrm{abr}$. 2008.

CASTELLS, M. A sociedade em rede. 8.ed. São Paulo: Paz e Terra, 2005. V. 1 .

CHAUI, M. Cultura e democracia: o discurso competente e outras falas. 10. ed. São Paulo: Cortez, 2003.

CHESNAIS, F. A mundialização do capital. São Paulo: Xamã, 1996.

CORREIA, A. M. R. Information Literacy for active and effective citizenship, jul. 2002 [White paper prepared for Unesco, The U.S. National Commission on Libraries and Information Science, and the National Forum on Information Literacy, for use at the Information Literacy Meeting of Experts, Prague, The Czech Republic]. Disponível em: $<$ http://www.nclis.gov/libinter/infoliticons\&meet/papers/correia-

fullpaper.pdf>. Acesso em: 20 mai. 2005.

DUDZIAK, E. A.; FERREIRA, S. M. S.P. A information literacy e o papel educacional das bibliotecas. 2001. 173 f. Dissertação (Mestrado em Ciência da Informação) - Escola de Comunicação e Artes, Universidade do Estado de São Paulo, São Paulo, 2001

LÉVY, P. Cibercultura. São Paulo: Ed. 34, 1999.

MAMEDE, G. Hipocrisia: o mito da cidadania no Brasil. Revista de Informação Legislativa, Brasília, v. 34, n. 134, p. 219-229, abr./jun. 1997.

MIRANDA, S. V. Identificando competências informacionais. Ciência da Informação, Brasília, v.33, n.2, p.112-122, maio/ago. 2004.

MOORE, N. A sociedade da informação. In: A INFORMAÇÃO: tendências para o novo milênio. Brasília: IBICT, 1999. p.94-108.

MOSCO, V. Repensando e renovando a economia política da informação. Perspectivas em Ciência da Informação, Belo Horizonte, v.3, n.2, p.97114, jul./dez. 1998.

RIOS, T. A. Ética e competência. 11. ed. Petrópolis: Cortez, 2001. 
SARACEVIC, T. Ciência da informação: origem, evolução e relações. Perspectivas em Ciência da Informação, Belo Horizonte, v.1, n.1, p. 4162, jan./jun. 1996.

SHERA, J. H.; CLEVELAND, D. B. History and foundations of Information Science. Annual Review of Information Science and Technology (ARIST). Washington. n. 12, p. 249-275, 1977.

SIQUEIRA, S. M. M. Trabalho e educação: novas competências ou crise do capital? In: MENEZES, A. M. D.; FIGUEIREDO, F. F. (Orgs.). Trabalho, sociabilidade e educação: uma critica à ordem do capital. Fortaleza: UFC, 2003. p. 361-384.

TARGINO, M. G. Biblioteconomia, informação e cidadania. Revista da Escola de Biblioteconomia da UFMG, Belo Horizonte, v.20, n.2, p. 149160, jul./dez. 1991.

TOMASI, A. P. N. Qualificação ou competência? Educação \& Tecnologia, v. 7 , n. 1 , jan./jun. $2002 . \quad$ Disponível em: <http://www2.cefetmg.br/dppg/revista/arqRev/revistan7v1artigo7.pdf $>$. Acesso em: 20 ago. 2006. 